\title{
Tratamiento de desechos orgánicos empleando microorganismos celulíticos
}

\section{Treatment of organic waste at family Aldaz's slaughterhouse, employing} cellulolytic microorganisms

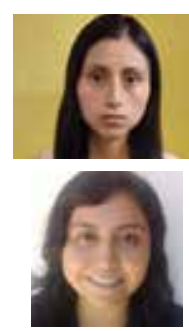

Nacimba Nacimba Gabriela Alexandra

Ingeniera Ambiental

e-mail: ganacimba@uce.edu.ec

Santafé Sari Diana Carolina

Ingeniera Ambiental

e-mail: dianasantafesari@g mail.com

\section{Félix Daniel Andueza Leal}

Ph.D. en Microbiología y Parasitología

Docente Facultad de Ingeniería en Geología, Minas, Petróleos y

Ambiental de la Universidad Central del Ecuador

e-mail: fdandueza@uce.edu.ec

\section{Resumen}

La presente investigación utilizó un diseño experimental completamente al azar (DCA), con 3 tratamientos (T1, T2 y T3) y un blanco (TB) como referencia, cada uno con 3 repeticiones, con un total de 12 pilas de compost, ubicadas en la parroquia de Amaguaña. Cada pila estuvo contenia $132 \mathrm{Kg}$ de estiércol y contenido ruminal provenientes del camal de faenamiento familia Aldaz; 30 gdeurea, 4L de melaza y 4Kg de aserrín; se inocularon para el tratamiento T1 con 30 x 109 UFC de Proteus mirabilis, T2 con 30 x 109 UFC de Citrobacter freundii, T3 con 356 x 103 células Penicillium spp. y TB sin adición de microorganismos. Se tomaron mediciones de temperatura, $\mathrm{pH}$ y humedad a los 3 días de creación de las pilas (tiempo de adaptación de microorganismos a su nuevo hábitat). El análisis de varianza (ANOVA), determinó que no existieron diferencias estadísticamente significativas entre tratamientos, por ello para seleccionar el mejor tratamiento se emplearon indicadores cuantitativos y cualitativos. Como resultado T2 fue el mejor tratamiento con una reducción en la cantidad de desechos orgánicos del 80,97\%; una Tmáx de $46^{\circ} \mathrm{C}$, materia orgánica del $80,02 \%$, produciendo un sustrato orgánico marrón oscuro altamente salino con $\mathrm{pH} 9,04$, nitrógeno total $(4 \%)$, fósforo total $(0,02 \%)$, potasio $(0,73 \%)$ y libre de patógenos fecales.

Palabras clave: compost; tratamientos; inóculo; sustrato orgánico; microorganismos

\section{Abstract}

The present investigation used a completely randomized experimental design (DCA), with 3 treatments (T1, T2 and T3) and a target (TB) as reference, each with 3 repetitions, with a total of 12 compost piles, located in the parish of Amaguaña. Each pile contained $132 \mathrm{~kg}$ of manure and rumen content from the Aldaz family slaughterhouse; $30 \mathrm{~g}$ of urea, $4 \mathrm{~L}$ of molasses and $4 \mathrm{Kg}$ of sawdust; were inoculated for T1 treatment with $30 \times 109$ CFU of Proteus mirabilis, T2 with $30 \times 109$ CFU of Citrobacter freundii, T3 with $356 \times 103$ cells Penicillium spp. and TB without addition of microorganisms. Measurements of temperature, $\mathrm{pH}$ and humidity were taken 3 days after the creation of the batteries (time of adaptation of microorganisms to their new habitat). The analysis of variance (ANOVA), determined that there were no statistically significant differences between treatments, so to select the best treatment quantitative and qualitative indicators were used. As a result T2 was the best treatment with a reduction in the amount of organic waste of $80,97 \%$; a Tmax of $46{ }^{\circ} \mathrm{C}$, organic matter of 80,02\%, producing a highly saline dark brown organic substrate with pH 9.04, total nitrogen (4\%), total phosphorus (0,02\%), potassium (0,73\%) ) and free of fecal pathogens.

Keywords: compost; treatments; inoculum; organic substrate; microorganisms 


\section{Introducción}

De los residuos generados a nivel nacional se ha determinado que el 60\% corresponden a residuos orgánicos y $20 \%$ a residuos sólidos inorgánicos potencialmente reciclables, una fuente importante de generación de estos se encuentra en los más de 200 mataderos o centros de faenamiento. A nivel nacional se estima que 15,6 millones de litros es sangre, 48,138 TN es contenido ruminal y 19,255 TN es estiércol (MAE, 2013).

Se estima que del proceso de faenado, el $25 \%$ del peso total del animal vivo es residuo entre ellos tenemos: estiércol, contenido ruminal, sangre, huesos, tejidos grasos, entre otros. El tratamiento de estos desechos a partir de la recuperación, reutilización y transformación en insumos aprovechables, es primordial debido a que en Ecuador la mayoría de camales presenta una mala disposición del estiércol, ya que este es depositado a cielo abierto, en quebradas, lotes baldíos, entre otros.

Esto ha provocado graves problemas de contaminación ambiental en cuerpos hídricos principalmente por microorganismos patógenos para el hombre, en el suelo alterar sus condiciones debido a que contienen metales pesados que con la precipitación llegan a formar lixiviados, por otro lado, en el aire generan un desequilibrio debido al porcentaje de metano y monóxido de carbono que emanan alterando las características naturales del entorno.

Como precedentes de este trabajo se incluyen, experimentos realizados principalmente en el continente asiático, en países como: China, Japón y Corea del Sur, en los cuales se han aislado cepas específicas de microorganismos como lactobacilos, actinomicetos, hongos, entre otros, evaluando sus capacidades de degradación de celulosa, su actividad anti fúngica en los casos donde era posible, secuenciaron su ADN para identificarlas y caracterizarlas, y por último las emplearon en la elaboración de abono orgánico teniendo como resultado que al adicionar estas cepas el proceso de compostaje mejora notablemente, ya que la temperatura como indicador fundamental del proceso aumenta considerablemente en los primeros días de la creación de las pilas de compost lo cual reduce el tiempo de maduración del abono orgánico. (Jia et al., 2011)

Tras el análisis del funcionamiento del camal de faenamiento familia Aldaz, se detectó que uno de los mayores problemas ambientales es la generación de estiércol vacuno que normalmente, debido al desconocimiento, a la falta de un espacio físico adecuado son enterrados o dejados almacenados a la intemperie, con la consecuente contaminación ambiental. Por ello, se planteo como alternativa para el manejo de estos desechos transformarlos en un sustrato orgánico mediante el proceso de compostaje permitiendo convertir y transformar de manera segura los residuos orgánicos, para aprovechar en la industria agrícola, generando beneficios económicos y ambientales para la empresa ya que el producto generado aumentará el aporte de nutrientes, la retención de agua y oxígeno en suelos degradados.

\section{Metodología}

\section{Recolección de muestras}

Se recolectó muestras de estiércol y contenido ruminal "in situ" en el camal de faenamiento Familia Aldaz, con la finalidad de aislar microorganismos celulolíticos presentes en aquellos residuos. Se empleó el método propuesto por Leguizamon y Tique, (2008) se trazó una malla sobre el material a recolectar y se procedió a tomar muestras de las intersecciones de dicha malla.

Las muestras se recolectaron con una espátula esterilizada con alcohol al $70 \%$, se las mezcló en un balde plástico, la muestra compuesta fue introducida en bolsas Ziploc estériles con objeto de mantener la humedad. Para transportar la muestra se usó un cooler que mantuvo la cadena de frío, evitando la reproducción y metabolismo de microorganismos nativos.

\section{Aislamiento de microorganismos con actividad celulolítica}

Se utilizó $1 \mathrm{~L}$ de medio mineral líquido $\left(\mathrm{NaNO}_{3}: 2,5\right.$ g; $\mathrm{KH}_{2} \mathrm{PO}_{4}$ : 2,0 g; $\mathrm{MgSO}_{4}$ : 0,2 g; $\mathrm{NaCl}: 0,2 \mathrm{~g}$ y Ca$\mathrm{Cl}_{2} \bullet 6 \mathrm{H}_{2} \mathrm{O}: 0,1 \mathrm{~g}$, en $1 \mathrm{~L}$ de agua destilada, para revitalizar los microorganismos presentes en el estiércol y contenido ruminal. Para asegurar que únicamente proliferen los microorganismos aerobios que presenten actividad celulolítica, se usó como fuente de carbono papel filtro, en una proporción del 3\% respecto a la cantidad total de medio mineral. El papel filtro se lo cortó en trozos de aproximadamente $1 \mathrm{~cm}$. Se esterilizó vía calor húmedo en autoclave durante 15 min hasta alcanzar los $121^{\circ} \mathrm{C}$ y $1 \mathrm{~atm}$ de presión.

Se elaboró un biorreactor, que contenía $1 \mathrm{~L}$ de medio mineral esterilizado y frío con el 3\% de inóculo, es decir, $30 \mathrm{~g}$ de la muestra de estiércol y contenido ruminal y $30 \mathrm{~g}$ de papel filtro, este proceso se llevó a cabo a temperatura ambiente $\left(20^{\circ} \mathrm{C}\right)$ y con $2 \mathrm{~g} / \mathrm{L}$ de 02 .Se realizaron observaciones cada 5 días, paraapreciar la degradación del papel filtro y controlar temperatura y la cantidad de oxígeno, este proce-so se lo hizo durante 15 días. El día 12 se detectó la suspensión del aumento de la temperatura del biorreactor, por lo que se cubrió con material con-centrador de calor y se colocó cerca lámparas. El tiempo de observación se extendió a 17 días luego de los cuales se realizó la siembra de bacterias y hongos en medios específicos.

\section{Identificación y selección de microrganismos celulolíticos. Cepas bacterianas.}

- Macroscopía. Se realizó la siembra de bacterias en medio TSA se llevó a incubación durante 48 h a $37^{\circ} \mathrm{C}$, posteriormente se realizó la caracterización 
macroscópica, con base en los siguientes criterios: "tamaño de las colonias (puntiforme, pequeñas, medianas, grandes); color; forma (regulares, redondas, ovaladas, irregulares, filamentosas, rizoides); elevación de las colonias (plana, elevada, convexa monticular); bordes (entero, ondulado, aserrado, filamentoso y rizado); superficie; olor (amoniacal, fétido, dulzón) y crecimiento (abundante, moderado, escaso)" (Escobar, et al., 2012).

- Microscopía. Se procedió a realizar el aislamiento de las cepas identificadas en macroscopía, para ello se preparó $350 \mathrm{~mL}$ de caldo nutritivo $\mathrm{BH}$ y se colocó $50 \mathrm{~mL}$ en 7 matraces, por el método de inoculación directa fueron tomadas las diferentes colonias con el asa de siembra, colocadas en los matraces (Laboratorios Britania S.A, 2015), y llevados a la incubadora por 24 horas. Transcurrido este periodo se utilizó las cepas en las diferentes pruebas bioquímicas, para identificar la especie de bacteria.

\section{Cepas fúngicas}

- Macroscopía. Se realizó la siembra de hongos en medio Agar Sabouraud, su proliferación demoró sietedías a temperatura ambiente; posteriormente se observó los bordes, exudado, color, olor, forma y claves taxonómicas (Escobar et al., 2012) de los hongos desarrollados

- Microscopía. Para la observación microscópica, se utilizó la técnica de cinta pegante. Esta técnica, se realizó mediante el doblez de una tira de cinta adhesiva la que se presionó firmemente contra la superficie del hongo a identificar. La tira de cinta con la muestra fúngica, se colocó en un portaobjetos y se añadió una gota de azul de lactofenol, finalmente se observó en el microscopio.

\section{Preparación de inóculos}

\section{Se realizó la reactivación de las cepas seleccionadas me- diante la adición de nutrientes}

Bacterias. Fueron reactivadas en caldo $\mathrm{BHI}$, para esto se definió la escala Macfarland en la que se encontraban los microorganismos, que para el caso de Proteus mirabilis (M3) y Citrobacter freundiii (M13) se encontraban en escala 10 Macfarland, posteriormente se los introdujo en la incubadora a $37^{\circ} \mathrm{C}$ durante 24 horas (Universidad de Antioquia, 2009).

Hongo. Para Penicilium spp., se sembró sus esporas en $8 \mathrm{~mL}$ de caldo BHI, se llevó a incubación a 67 ${ }^{\circ} \mathrm{C}$ por 24 horasy se realizó el recuento celular en la cámara de Neubauer.

La concentración celular según Arredondo et al., (1997) se calcula de acuerdo a la fórmula:

$\mathrm{C}=\mathrm{N} * 10^{4 *}$ dil

En donde:

$\mathrm{C}=\mathrm{cél} / \mathrm{mL}$

$\mathrm{N}=$ promedio de células presentes en $1 \mathrm{~mm}^{2}(0,1 \mu \mathrm{L})$ dil = factor de dilución
Una vez reactivadas, la cantidad de inóculopara las pilas de compost, fue seleccionada de forma aleatoria y experimental considerando el recuento celular fúngico y la escala Macfarland.

Los inóculos fueron colocados en tubos de ensayo estériles debidamente sellados, etiquetados y llevadosal área experimental en cooler manteniendo la cadena de frío.

Los inóculos fueron colocados en el centro de las pilas a una profundidad aproximada de $30 \mathrm{~cm}$.

\section{Pilas de compost}

Los materiales empleados para la creación de pilas de compost fueron: estiércol vacuno, contenido ruminal, aserrín, urea y melaza. La cantidad de material empleado se determinó de manera experimental; con una relación C: N inicial calculada de 34,15, este valor se encuentra dentro del rango óptimo establecido por la $\mathrm{FAO}(2013)$.

Se crearon 12 pilas de compost, cada tres pilas fueron asignadas con un tratamiento específico. Las pilas fueron creadas sobre plástico lo cual facilitó su recubrimiento, la retención de los materiales a compostar y la prevención de contaminación del suelo con lixiviados.

\section{Parámetros de control durante el proceso de compostaje}

Antes de iniciar con el proceso de control, se realizó un recuento inicial de bacterias y hongos, a fin de asegurar su presencia en las pilas de compost. Se realizó a los 3 días de creación de las pilas, para ello se tomaron $2,5 \mathrm{~g}$ de cada pila de compost y se adicionaron $50 \mathrm{~mL}$ de agua destilada, se homogenizó las soluciones madre por agitación y mediante el método de diluciones seriadas (hasta 10-4) se procedió a la siembra por extensión de bacterias en agar Antibiótico 19 con un periodo de incubación de $48 \mathrm{~h}$ a $35^{\circ} \mathrm{C}$ y hongos en agar OGY con periodo de siete días para su desarrollo.

Posteriormente, se controlaron parámetros como: temperatura, $\mathrm{pH}$, aireación y humedad, durante todo el proceso de compostaje, según lo indica la Tabla 3(pág.4). Los datos registrados permitieron realizar correcciones in situ a fin de que el proceso produjera un compost inocuo y con cantidades óptimas de macro nutrientes.

\section{Análisis físicos, químicos y microbiológicos en compost maduro.}

Los análisis físicos, químicos y microbiológicos sobre muestras de compost maduro, se realizaron en: el laboratorio de Química Agrícola y Suelos de la Facultad de Ciencias Agrícolas y en los laboratorios del Centro de Biología de la Universidad Central del Ecuador, respectivamente. Los análisis físicos realizados se basaron en el aspecto general de la pila de compost, es decir, se evaluó su color y olor. Los análisis químicos realizados fueron la temperatura, 
el $\mathrm{pH}$, el porcentaje de humedad, el porcentaje de materia orgánica, conductividad eléctrica, nitrógeno, fósforo y potasio. Mientras que los análisis microbiológicos comprenden: presencia de Coliformes fecales (E. coli) y Coliformes totales.

Además, se realizó el conteo final de bacterias y hongosa fin de comparar la disminución de microrganismos debido al efecto propio del proceso de compostaje.Se lo realizó a los 88 días de creación de las pilas, una vez terminado el proceso de compostaje

En la Tabla 2 se muestran los análisis realizados y sus respectivos métodos.

\section{Indicadores para evaluación del mejor tratamiento}

Estos indicadores se aplicaron para evaluar cada tratamiento debido a que no se pudo realizar la prueba de Tukey ya que no existió diferencia significativamente estadística entre tratamientos.

Los indicadores cualitativos fueron: Color: marrom oscuro; y olor: a tierra. Mientras los indicadores cuantitativos se muestran en la Tabla 3, y permitieron definir qué tratamiento fue el mejor en términos de calidad de compost maduro, reducción del tiempo del proceso de compostaje y características del microorganismo inoculado.

Tabla 1. Parámetros de control.

\begin{tabular}{|c|c|c|c|c|c|}
\hline $\begin{array}{c}\text { Parámetros de } \\
\text { control }\end{array}$ & Método & $\begin{array}{c}\text { Aparato de } \\
\text { medición }\end{array}$ & $\begin{array}{c}\text { Marca del } \\
\text { aparato }\end{array}$ & $\begin{array}{l}\text { Lugar de } \\
\text { medición }\end{array}$ & $\begin{array}{c}\text { Frecuencia de } \\
\text { medición }\end{array}$ \\
\hline Temperatura & $\begin{array}{l}\text { Lectura directa } \\
\text { del aparato }\end{array}$ & $\begin{array}{c}\text { Termómetro } \\
\text { digital }\left(-50^{\circ} \mathrm{C}\right. \\
\left.-\quad+300^{\circ} \mathrm{C}\right)\end{array}$ & SUNNEX & In situ & $\begin{array}{c}\text { Dos veces a } \\
\text { la semana }\end{array}$ \\
\hline $\mathrm{pH}$ & Química seca & $\begin{array}{c}\text { Tiras } \\
\text { indicadoras } \\
\text { del } \mathrm{pH}\end{array}$ & Merck & In situ & $\begin{array}{c}\text { Dos veces a } \\
\text { la semana }\end{array}$ \\
\hline Aireación & $\begin{array}{c}\text { Volteo manual } \\
\text { de pilas }\end{array}$ & $\mathrm{N} / \mathrm{A}$ & N/A & In situ & $\begin{array}{c}\text { Dos veces a } \\
\text { la semana }\end{array}$ \\
\hline Humedad & $\begin{array}{c}\text { Método } \\
\text { gravimétrico } \\
\text { de desecación } \\
\text { en estufa de } \\
\text { aire caliente }\end{array}$ & $\begin{array}{c}\text { Estufa de aire } \\
\text { caliente } \\
\text { Balanza } \\
\text { analítica }\end{array}$ & $\begin{array}{c}\text { Memmert } \\
\text { ADAM }\end{array}$ & LABFIGEMPA & $\begin{array}{l}\text { Una vez a } \\
\text { la semana }\end{array}$ \\
\hline
\end{tabular}

Tabla 2 Métodos de ensayo para compost maduro

\begin{tabular}{|c|c|}
\hline Determinación de análisis microbiológicos & Método \\
\hline $\begin{array}{l}\text { Coliformes fecales } \\
\text { Coliformes totales }\end{array}$ & $\begin{array}{l}{ }^{1} \text { Recuento por el número más probable } \\
\text { Recuento por el número más probable }\end{array}$ \\
\hline Determinación de parámetros químicos & Método \\
\hline Conductividad eléctrica & Conductímetro con extracto de pasta saturada. \\
\hline Materia orgánica & Calcinación de la muestra en mufla a $600^{\circ} \mathrm{C}$. \\
\hline Nitrógeno total & Cálculo a partir del porcentaje de materia orgánica. \\
\hline Fosforo total & Método Olsen modificado. \\
\hline Potasio & Espectrofotometría de absorción atómica. \\
\hline
\end{tabular}

Tabla 3. Indicadores cuantitativos.

\begin{tabular}{|c|c|c|}
\hline Parámetros de evaluación & Variables de salida & Indicador \\
\hline $\begin{array}{l}\text { Duración del proceso de } \\
\text { compostaje }\end{array}$ & Tiempo de compostaje & $\left(t_{r e}{ }^{1} / t_{r f}^{2}\right)^{*} 100$ \\
\hline \multirow{4}{*}{$\begin{array}{l}\text { Calidad de compost maduro } \\
\text { (Análisis físicos, químicos y } \\
\text { microbiológicos) }\end{array}$} & $\begin{array}{c}\text { Temperatura } \\
\text { pH } \\
\text { Humedad }\end{array}$ & \multirow{4}{*}{$\begin{array}{c}\left(\mathrm{T}_{\mathrm{re}} / \mathrm{T}_{\mathrm{rf}}\right)^{*} 100 \\
\left(\mathrm{pH} \mathrm{H}_{\mathrm{re}} / \mathrm{pH}_{\mathrm{rf}}\right)^{*} 100 \\
\left(\mathrm{H}_{\mathrm{re}} / \mathrm{H}_{\mathrm{rf}}\right)^{*} 100 \\
\left(\% \mathrm{M} . \mathrm{O}_{\mathrm{re}} / \% \mathrm{M} . \mathrm{O}_{\mathrm{rf}}\right. \\
)^{*} 100 \\
(\% \text { material } \\
\text { degradado } / \% \text { material } \\
\text { degradado })^{*} 100 \\
\left(\mathrm{C} . \mathrm{E}_{\mathrm{rr}} / \% \mathrm{C}_{\mathrm{rf}} \mathrm{E}_{\mathrm{rf}}\right)^{*} 100 \\
\left(\% \mathrm{~N}_{\mathrm{re}} / \% \mathrm{~N}_{\mathrm{rf}}\right)^{*} 100 \\
\left(\% \mathrm{P}_{\mathrm{re}} / \% \mathrm{P}_{\mathrm{rf}}\right)^{*} 100 \\
\left(\% \mathrm{~K}_{\mathrm{re}} / \% \mathrm{~K}_{\mathrm{rf}}\right)^{*} 100 \\
<1000 \mathrm{NMP} / \mathrm{g}\end{array}$} \\
\hline & Materia orgánica & \\
\hline & $\begin{array}{l}\text { Cantidad de material } \\
\text { degradado }\end{array}$ & \\
\hline & $\begin{array}{c}\text { Conductividad eléctrica } \\
\text { Nitrógeno total } \\
\text { Fósforo total } \\
\text { Potasio } \\
\text { Coliformes fecales }\end{array}$ & \\
\hline
\end{tabular}


Para esta investigación se empleó un diseño completamente al azar (DCA) por ser un método ampliamente usado en el campo de la experimentación agrícola y a nivel de invernaderos. Este diseño tiene una amplia aplicación cuando las unidades experimentales son bastante homogéneas, es decir que los factores actúan por igual en estas unidades.

Este análisis estadístico conjuntamente con los indicadores anteriormente mencionados permitió seleccionar el tratamiento que redujo la mayor cantidad de desechos orgánicos y que produjo compost de buena calidad.

\section{Discusión de resultados}

\section{Recolección de muestras}

Se recolectó una muestra compuesta de $200 \mathrm{~g}$ de estiércol y contenido ruminal para realizar el aislamiento de microrganismos celulolíticos aerobios nativos.

\section{Identificación y selección de microorganismos con actividad celulolítica}

\section{Bacterias}

De las cajas inoculadas para crecimiento de bacterias se consideraron como resultados estadísticamente válidos a los expuestos en la Tabla 4.

Tabla 4. Placas Petri estadísticamente válidas.

\begin{tabular}{cc}
\hline Dilución & $\begin{array}{c}\text { Cantidad de colonias } \\
\text { UFC/g }\end{array}$ \\
\hline $10^{-1}$ & $1,1 \times 10^{4} \mathrm{UFC} / \mathrm{g}$ \\
$10^{-2}$ & $3,5 \times 10^{4} \mathrm{UFC} / \mathrm{g}$ \\
\hline
\end{tabular}

UFC: Unidades formadoras de colonia

En estas cajas las colonias bacterianas fueron evaluadas con los criterios macroscópicos precedentes. Así, en la Tabla 5. se muestra la macroscopía observada.

Tabla 5

\begin{tabular}{|c|c|}
\hline $\begin{array}{l}\text { Código } \\
\text { de } \\
\text { colonia }\end{array}$ & Macroscopia de las colonias identificadas \\
\hline M1 & $\begin{array}{l}\text { Redondas cóncavas, de borde irregular y de } \\
\text { color crema. }\end{array}$ \\
\hline M3 & $\begin{array}{l}\text { Cóncavas, de borde regular, rosadas y } \\
\text { chiclosas. }\end{array}$ \\
\hline M4 & $\begin{array}{l}\text { Cóncavas, de borde regular y coloración } \\
\text { amarilla }\end{array}$ \\
\hline M6 & Concavas, de borde regular y de color crema \\
\hline M8 & $\begin{array}{l}\text { Cóncavas, de borde regular y coloración } \\
\text { amarillo intenso }\end{array}$ \\
\hline M11 & $\begin{array}{l}\text { Cóncavas, de borde regular, rosadas y con } \\
\text { un punto central muy notorio. }\end{array}$ \\
\hline M13 & $\begin{array}{l}\text { Convexas, de borde irregular y de color } \\
\text { crema. }\end{array}$ \\
\hline
\end{tabular}

La Microscopía se realizó mediante pruebas bioquímicas según lo expuesto por Madigan et al., (2009), se realizaron seis pruebas que se indican en la Tabla 6.

Con los resultados obtenidos de las pruebas bioquímicas más los criterios macroscópicos y las características específicas de las diferentes especies bacterianas descritasteóricamente, se seleccionaron para la investigación las cepas de las especies Proteus mirabilis y Citrobacter freundii.

\section{Cepas fúngicas}

En las cajas inoculadas para crecimiento dehongos, se evidenció el crecimiento de una única especie de hongo de color verdoso, algodonoso y amarillo en su parte posterior (Fig. 1), que mediante la técnica de la cinta pegante y el microcultivo (Martí et al., 1998) se observó la morfología típica del genero Penicillium (Fig 2.).Género que se caracteriza por la degradación de materia orgánica; por consiguiente, también se empleó a la cepa fúngica Penicillium spp.para el desarrollo de la investigación.

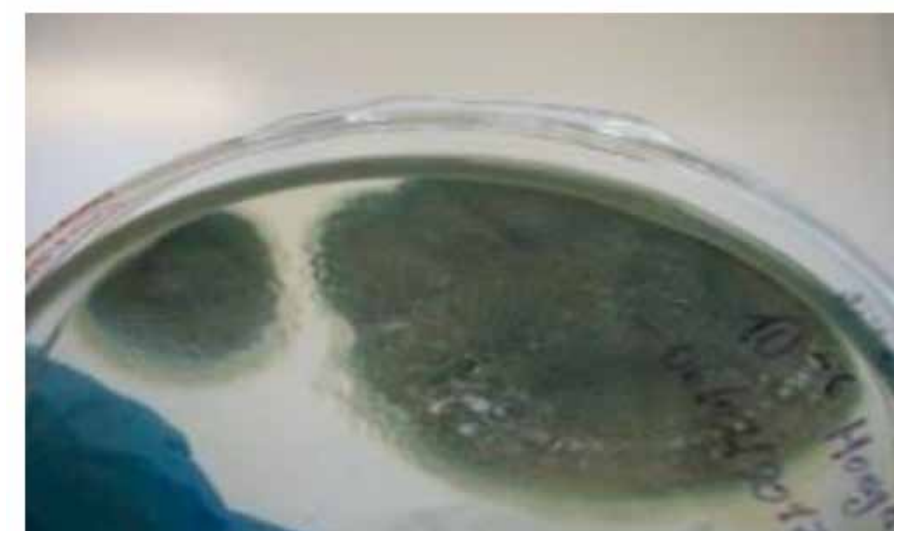

Fig. 1. Macroscopía de cepa fúngica: Hongo verdoso

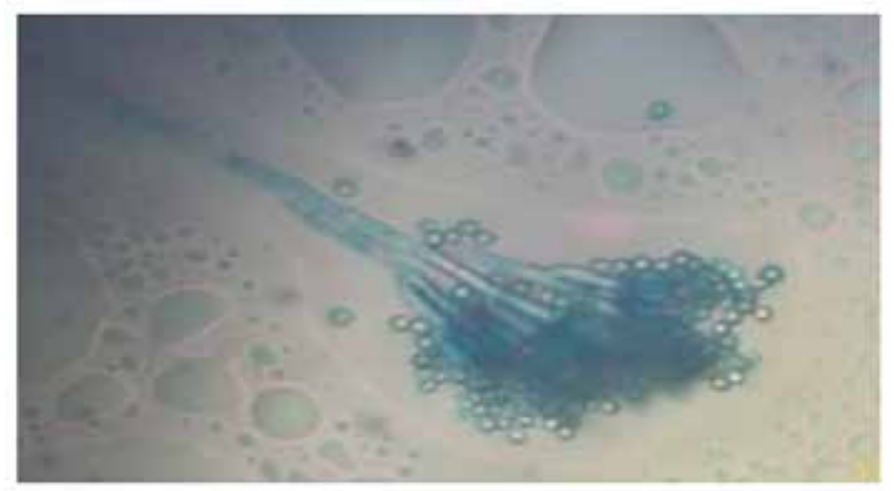

Fig. 2. Morfología de Penicillium spp. 
Tabla 6. Resultado de pruebas bioquímicas.

\begin{tabular}{|c|c|c|c|c|c|c|c|c|c|}
\hline \multirow{2}{*}{$\begin{array}{l}\text { Código } \\
\text { colonia }\end{array}$} & \multirow{2}{*}{$\begin{array}{c}\text { Tinción } \\
\text { Gram }\end{array}$} & \multirow{2}{*}{ Oxidasa } & \multirow{2}{*}{ Catalasa } & \multirow{2}{*}{$\begin{array}{l}\text { Citrato } \\
\text { Simmons }\end{array}$} & \multicolumn{2}{|c|}{ SIM } & \multicolumn{3}{|c|}{ TSI } \\
\hline & & & & & Movilidad & $\mathrm{H}_{2} \mathrm{~S}$ & $\begin{array}{l}\text { Pico } \\
\text { /fondo }\end{array}$ & Gas & $\mathrm{H}_{2} \mathrm{~S}$ \\
\hline M1 & - & - & - & - & + & - & $\mathrm{K} / \mathrm{A}$ & - & - \\
\hline M3 & + & + & - & + & + & + & NA & + & + \\
\hline M4 & - & - & - & - & + & - & K/A & - & - \\
\hline M6 & + & - & - & - & + & - & AVA & + & - \\
\hline M8 & - & - & - & - & - & - & KIA & - & - \\
\hline M11 & - & + & - & - & - & - & $\mathrm{K} / \mathrm{K}$ & - & - \\
\hline M13 & - & - & + & - & + & + & NA & + & + \\
\hline
\end{tabular}

\section{Preparación de inóculos}

Resultados del recuento celular para Penicillum spp. en la cámara de Neubauer mostrados en la Tabla 7.

Tabla 7. Conteo de células para Penicillum spp.

\begin{tabular}{cc}
\hline Cuadricula & $\begin{array}{c}\text { Número de } \\
\text { células } / \mathrm{mL}\end{array}$ \\
\hline A & 194 \\
B & 38 \\
C & 45 \\
D & 79 \\
TOTAL & 356 \\
PROMEDIO & 89 \\
\hline
\end{tabular}

Las cantidades de inóculo empleadas para cada tratamiento descritas en la Tabla 8.

Tabla 8. Cantidad de inóculo por pila de compost.

\begin{tabular}{cccc}
\hline $\begin{array}{c}\text { Tratamient } \\
\text { os }\end{array}$ & $\begin{array}{c}\text { Microorganism } \\
\text { o a inocular }\end{array}$ & $\begin{array}{c}\text { Cantida } \\
\text { d de } \\
\text { inóculo } \\
\text { en } \\
\text { mL/pila }\end{array}$ & $\begin{array}{c}{ }^{1} \text { Cantidad total } \\
\text { de } \\
\text { microorganism } \\
\text { os }\end{array}$ \\
\hline \multicolumn{5}{c}{$\begin{array}{c}\text { Proteus } \\
\text { mirabilis }\end{array}$} & 10 & $30 \times 10^{9} \mathrm{UFC}$ \\
T1 & $\begin{array}{c}\text { Citrobacter } \\
\text { freundii }\end{array}$ & 10 & $30 \times 10^{9}$ UFC \\
T2 & $\begin{array}{c}\text { Penicillium } \\
\text { spp. }\end{array}$ & 0,4 & $356 \times 10^{3}$ \\
T3 & $\begin{array}{c}\text { Sin adición de } \\
\text { microorganism } \\
\text { os }\end{array}$ & 0 & N/A AS \\
TB & 0 & \\
\hline & 1Total de microorganismos presentes en la cantidad total \\
de inóculo aplicado por pila de compost.
\end{tabular}

Pilas de compost

Las cantidades de materiales utilizados para cada pila de compost, se encuentran detalladas en la Tabla 9 .
Tabla 9

\begin{tabular}{cc}
\hline Material de partida & $\begin{array}{c}\text { Cantidad } \\
\text { es }\end{array}$ \\
\hline $\begin{array}{c}\text { Estiércol vacuno + contenido } \\
\text { ruminal }\end{array}$ & $132 \mathrm{Kg}$ \\
Aserrin & $4 \mathrm{Kg}$ \\
Urea & $30 \mathrm{~g}$ \\
Melaza & $4 \mathrm{~L}$ \\
\hline
\end{tabular}

Análisis físicos, químicos y microbiológicos en compost maduro

El recuento inicial y final de bacterias y hongos en las pilasse observan en las Tablas 10 y 11.

Tabla 10. Recuento inicial de bacterias dilución $\mathbf{1 0}^{-1}$

\begin{tabular}{|c|c|c|c|}
\hline Tratamiento & Repetición & $\begin{array}{c}\text { R. inicial } \\
\text { UFC/g }\end{array}$ & $\begin{array}{l}\text { R. final } \\
\text { UFC/g }\end{array}$ \\
\hline & R1 & $9,7 \times 10^{2}$ & $1,4 \times 10^{2}$ \\
\hline \multirow[t]{3}{*}{ TB } & R2 & $4,7 \times 10^{2}$ & - \\
\hline & R3 & $7,2 \times 10^{2}$ & - \\
\hline & R1 & $4,3 \times 10^{2}$ & $2,8 \times 10^{2}$ \\
\hline \multirow[t]{3}{*}{ T1 } & $\mathrm{R} 2$ & $4,4 \times 10^{2}$ & $1,5 \times 10^{2}$ \\
\hline & R3 & $5,1 \times 10^{2}$ & $3,2 \times 10^{2}$ \\
\hline & R1 & $4,0 \times 10^{2}$ & - \\
\hline \multirow[t]{2}{*}{ T2 } & $\mathrm{R} 2$ & $3,7 \times 10^{2}$ & $0,4 \times 10^{2}$ \\
\hline & R3 & $3,9 \times 10^{2}$ & - \\
\hline
\end{tabular}

Se tomó la dilución $10^{-1}$ debido a que se encuentra en el rango estadisticamente válido de 30 y 300 UFC. 
Tabla 11. Recuento inicial de hongos.

\begin{tabular}{|c|c|c|c|c|}
\hline Tratamiento & Repetición & $\underset{1}{\text { Dilución }}$ & $\begin{array}{c}R . \\
\text { inicial } \\
\text { UFC/g }\end{array}$ & $\begin{array}{c}R . \\
\text { final } \\
\text { UFC/g }\end{array}$ \\
\hline \multirow{12}{*}{ T3 } & \multirow{4}{*}{ R1 } & $10^{-1}$ & - & 5 \\
\hline & & $10^{-2}$ & 5 & 2 \\
\hline & & $10^{-3}$ & - & 1 \\
\hline & & $10^{-4}$ & 5 & - \\
\hline & \multirow{4}{*}{ R2 } & $10^{-1}$ & 1 & 1 \\
\hline & & $10^{-2}$ & 6 & 1 \\
\hline & & $10^{-3}$ & - & - \\
\hline & & $10^{-4}$ & 3 & - \\
\hline & \multirow{4}{*}{ R3 } & $10^{-1}$ & 2 & - \\
\hline & & $10^{-2}$ & 7 & 1 \\
\hline & & $10^{-3}$ & - & 1 \\
\hline & & $10^{-4}$ & 5 & - \\
\hline
\end{tabular}

Se observó que en la dilución $10^{-1}$ de crecimiento de cepas fúngicas en el recuento inicial, esto se debe a la aparición de setas de la especie de Coprinuscomatuscomo se muestra en las Figuras3 y 4 . Y el crecimiento de levaduras de la especie Rhodotorula, estas son colonias rojas brillantes y se muestra en la Figura 5. Ambas especies halladas pueden ser estudiadas en proyectos futuros como degradadores de hidrocarburos.

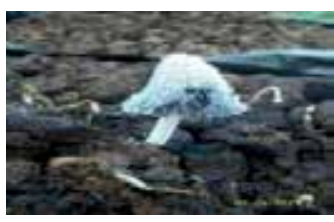

Figura 3. Seta de Coprinuscomatus

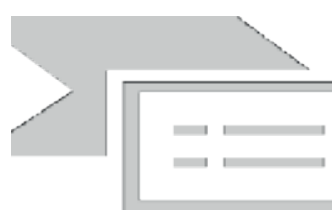

Figura 4. Esporas de Coprinuscomatus a 40X.

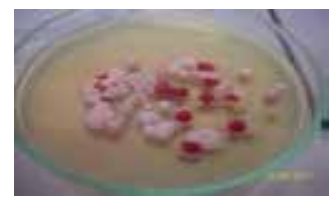

Figura 5. Levadura Rhodotorula

\section{Temperatura}

La fase del proceso de compostaje evaluada fue la fase termófila debido a que en ella el proceso alcanza la mayor temperatura del proceso, así, TB alcanzó $44{ }^{\circ} \mathrm{C}, \mathrm{T} 1: 44,9{ }^{\circ} \mathrm{C}, \mathrm{T} 2: 46,0{ }^{\circ} \mathrm{C}$ y T3: 42,5
${ }^{\circ} \mathrm{C}$. La FAO (2013) establece el rango óptimo para esta fase de $45^{\circ} \mathrm{C}$ a $70^{\circ} \mathrm{C}$. Según Pravia (2001) citado en Eche (2013) menciona el rango de $40^{\circ} \mathrm{C}$ a $75^{\circ} \mathrm{C}$ "para eliminar todos los organismos mesófilos patógenos, hongos, esporas, semillas y elementos biológicos indeseables". En estudios realizados por Gordillo y Chávez (2008), al usar poblaciones microbianas locales la temperatura fue menor a los $45^{\circ} \mathrm{C}$ mientras que al utilizar microorganismos comerciales la temperatura superó los $60^{\circ} \mathrm{C}$. De este modo, la existente entre los resultados de la investigación y estudios previos radica en la utilización de diferentes tipos de inóculos microbiológicos y materiales a compostar empleados.

\section{pH}

El pH final para el tratamiento T3 fue de 9,04 muy seguido del tratamiento $\mathrm{T} 2 \mathrm{con} \mathrm{pH}$ de 9,05, según la FAO este debe situarse entre 6,5 a 8,5 por lo que ningún tratamiento cumple con este parámetro. En la Norma Chilena 2880 (INC, 2003) los valores óptimos están ente 5 y 8,5 mientras que Olivares et al (2012) obtuvieron un pH de 7,42 con una remoción por semana, diferente al realizado en este estudio en el cual se removía cada tres días para controlar humedad. Mientras que Pérez et al (2008) obtuvo valores de 7,8. La diferencia se debe principalmente a la interacción del estiércol con los residuos vegetales utilizados, que para este estudio fue melaza, estiércol, aserrín y urea.

\section{Humedad}

El mayor porcentaje de humedad registrado en la investigación sucedió en T3 con 52,91\% muy superior al rango de la $\mathrm{FAO}$ que oscila entre 30 a $40 \%$, mientras que en la Norma Chilena 2280 (INC, 2003) está entre 30 y 45\%. Sin embargo, Pérez et al (2008) obtienen un valor de humedad de $52,2 \%$ al utilizar estiércol caprino y cascarilla de arroz, valor muy similar a los resultados obtenidos en el tratamiento T3.

\section{Materia orgánica}

El valor final máximo registrado fue $80,0 \%$ para T2; en estudios realizados por Pérez et al (2008) reporta $42,8 \%$ de materia orgánica en su producto final; sin embargo, Naranjo (2013) obtiene un valor de 23, 08\%. Según Abad et al. (1993) citado en Pérez et al (2008) reportó valores superiores al $80 \%$ en compost en residuos de origen animal que aseguran una mayor reserva de nutrientes, este valor coincide con el tratamiento T2, en la Tabla 12 se indican los resultados. 
Tabla 12. Porcentaje final de materia orgánica

\begin{tabular}{rc}
\hline Tratamiento & Media \% \\
\hline TB & 77,8 \\
T1 & 75,5 \\
T2 & 80,0 \\
T3 & 76,2 \\
\hline
\end{tabular}

\section{Cantidad de material degradado}

Se obtuvo un valor máximo de 82,5\%en T1 y un mínimo de $79,1 \%$ en T3 como se observa en la Tabla 13. La FAO (2013) menciona que durante el proceso de degradación se pierde hasta un 50\% de material inicial, en contraste con los datos de este estudio, se demuestra claramente que la utilización de inóculos microbiológicos mejora la reducción de las cantidades de materiales usados para la creación de pilas de compost. La elevada cantidad de material degradado es un "indicador de la velocidad de descomposición de la misma". Hernández, et al (2013).

Tabla 13. Porcentaje de material degradado

\begin{tabular}{rc}
\hline Tratamiento & Media $\%$ \\
\hline TB & 80,7 \\
T1 & 82,5 \\
T2 & 81,0 \\
T3 & 79,1 \\
\hline
\end{tabular}

\section{Conductividad eléctrica}

Los valores de conductividad eléctrica obtenidos oscilan entre 14,1-20,2 mmhos/cm, como se muestran en la Tabla 16, que al compararlos con valores de conductividad existentes en suelos muy salinos(mayores a $8 \mathrm{mmhos} / \mathrm{cm}$ ) se considera un sustrato orgánico altamente salino. Esta afirmación se corrobora según lo expuesto por Andrade (2016) donde se alcanzó un valor máximo de 9,13 mmhos/ $\mathrm{cm}$, siendo este un valor óptimo cuando se usan residuos animales según lo expone su investigación. Según la Norma Chilena 2880 (INC, 2003) para un compost clase $\mathrm{B}$ cuyo valor máximo de conductividad oscila entre 5-12 mmhos/cm. La conductividad eléctrica se encuentra directamente relacionado con la cantidad de sales disueltas en el compost esta tiende a aumentar durante el compostaje debido a la mineralización de la de la materia orgánica lo que a su vez genera el aumento en la concentración denutrientes, guarda relación con las concentraciones de $\mathrm{Ca}^{2+}, \mathrm{K}^{+}$y Na${ }^{+}$, (Cariello, et al, 2007).
Tabla 14. Conductividad eléctrica en compost maduro.

\begin{tabular}{rc}
\hline Tratamiento & Media $\%$ \\
\hline TB & 14,1 \\
T1 & 19,6 \\
T2 & 20,2 \\
T3 & 14,3 \\
\hline
\end{tabular}

\section{Nitrógeno}

El porcentaje de nitrógeno reportado oscila en el rango de $3,7 \%$ a $4,0 \%$ en base seca, según Tabla 15. Hernández, et al (2013) que oscilan entre $2 \%$ a $1,5 \%$, afirmando que el estiércol vacuno no es una buena fuente de aporte de nitrógeno en comparación con la gallinaza; afirmación que se contrapone con los resultados obtenidos en esta investigación. Olivares et al (2012), establecieron un porcentaje de nitrógeno del 2\%. Mientras, Andrade (2016) obtuvo un valor máximo de nitrógeno de 1,6\%, lo que indica que el compost obtenido en este estudio es rico en nitrógeno en comparación a productos provenientes de procesos de degradación similares.

\section{Tabla 15.Porcentaje de nitrógeno en compost maduro.}

\begin{tabular}{rc}
\hline Tratamiento & Media $\%$ \\
\hline TB & 3,9 \\
T1 & 3,7 \\
T2 & 4,0 \\
T3 & 3,8 \\
\hline
\end{tabular}

\section{Fósforo}

Se obtuvo entre 0,02\% y 0,03\% de fósforo según Tabla 16. valores que cumplen con el valor óptimo establecido para fósforo (menor o igual a $0,1 \%$ ) en la Norma Chilena 2880 (INC, 2003), lo cual alega que se trata de un compost con buena proporción de fósforo que será útil para "cultivos sensibles al stress de fósforo". (Norma Chilena 2880, 2003). Comercialmente, el compost obtenido no puede competir con otro tipo de abonos orgánicos, pues como lo expone Paul y Clarck (1996); citado en Soto y Muñoz (2002), un compost aceptable comercialmente presenta valores de fósforo dentro del rango óptimo de 0,15 a 1,5\%.

Tabla 16. Porcentaje de fósforo en compost maduro.

\begin{tabular}{rc}
\hline Tratamiento & Media \% \\
\hline TB & 0,03 \\
T1 & 0,03 \\
T2 & 0,02 \\
T3 & 0,02 \\
\hline
\end{tabular}

\section{Potasio}

Se reportaron valores de 0,73\% y 0,70\%, según Tabla 17, estos valores coinciden con la investigación 
realizada por Andrade (2016), donde el potasio se encuentra en un rango de $0,6 \%$ a $1,5 \%$. Datos similares $(1,05 \%$ de potasio) son reportados por Pérez, et al (2008). La FAO (2013), establece el rango óptimo de $0,3 \%$ a $1 \%$ que "mejora el régimen hídrico de la planta y aumenta su tolerancia a la sequía, heladas y salinidad." (FAO, 2013). Hernández, et al (2013) obtuvieron $0,55 \%$ de potasio, este valor también es reportado en el estudio de Castillo, et al (2010). Al igual que con el fósforo, existen factores que provocan una mayor o menor cantidad de potasio en el compost maduro.

Tabla 17.Cantidad de potasio en compost maduro.

\begin{tabular}{cc}
\hline Tratamiento & Media $\%$ \\
\hline TB & 0,70 \\
T1 & 0,73 \\
T2 & 0,73 \\
T3 & 0,73 \\
\hline
\end{tabular}

\section{Coliformes totales y fecales}

Los valores obtenidos según la Tabla 18 son muy bajos o nulos respecto al valor dado por la Norma Chilena 2880 (INC, 2003), donde un compost debe presentar valores menores a $1000 \mathrm{NMP} / g$ de coliformes fecales para ser considerado de buena calidad e inocuo. Estos bajos resultados demuestran que en la fase termófila la temperatura fue elevada durante el tiempo necesario para higienizar las pilas, eliminando patógenos como Escherichiacoli.

\section{Tabla 18. Recuento de colonias de Escherichiacoli}

\begin{tabular}{rc}
\hline Tratamiento & $\begin{array}{c}\text { E. Coli } \\
\text { NMP/mL }\end{array}$ \\
\hline TB & 18 \\
T1 & - \\
T2 & 3 \\
T3 & - \\
\hline
\end{tabular}

Resultados para dilución $10^{-1}$ NMP: número más probable; $\mathrm{mL}$ : mililitros

Por otro lado, para coliformes totales se reporta el valor máximo de 54 NMP para el tratamiento T1 como se muestra en la Tabla 19, este valor no puede ser comparado con el establecido en la Norma Chilena 2880 debido a que en ella se pide valores únicamente para el género Enterobacter y el grupo coliformes totales comprende más de un género de bacteria como: Klebsella, Citrobacter, Escherichia.
Tabla 19. Recuento de colonias de Coliformes totales

\begin{tabular}{cc}
\hline Tratamiento & $\begin{array}{c}\text { Coliformes } \\
\text { totales } \\
\text { NMP/mL }\end{array}$ \\
\hline TB & 500 \\
T1 & 54 \\
T2 & 277 \\
T3 & 346 \\
\hline
\end{tabular}

NMP: número más probable; $\mathrm{mL}$ : mililitros

\section{Conclusiones}

- Los desechos orgánicos provenientes del camal de faenamiento Familia Aldaz, fueron reducidos y tratados exitosamente al transformarlos en un producto aprovechable en el área agrícola, como lo es un sustrato altamente orgánico (80\% de materia orgánica) con porcentajes óptimos de macronutrientesy con baja o nula presencia de coliformes fecales.

- Los microorganismos con actividad celulolítica nativos aislados e identificados del contenido ruminal y estiércol vacuno en este estudio, corresponden a cepas bacterianas de Proteus mirabilis, Citrobacter freundii y la cepa fúngica Penicillium spp. Estos microorganismos presentaron una alta capacidad degradadora de desechos orgánicos (contenido ruminal y estiércol), lo que permitió reducir en un $80 \%$ la cantidad de materiales usados en las pilas de compostaje; demostrando que la utilización de microorganismos nativos es una solución óptima al momento de gestionar desechos orgánicos

- El mejor tratamiento para la conversión de desechos orgánicos a un compost de buena calidad, es el tratamiento T2, constituido por: estiércol vacuno, contenido ruminal, aserrín, melaza, urea y el inóculo de Citrobacter freundii. Este tratamiento presentó la mayor temperatura en la fase termófila $\left(46{ }^{\circ} \mathrm{C}\right)$, tiene un alto contenido de nitrógeno total $(4 \%)$, alto contenido de potasio $(0,73 \%)$, alto contenido de materia orgánica $(80 \%)$ y una tasa elevada de degradación de desechos (80,97\%), en comparación con los otros tratamientos

- Los factores que influyeron en la ralentización del proceso de compostaje fueron la gran variación de la temperatura y el porcentaje de humedad de los tratamientos durante el proceso de compostaje, estas variaciones sucedieron debido al mal dimensionamiento de la pila de compost, debido a que pilas de baja altura y de base ancha, hacen que el calor generado por los microorganismos se pierda fácilmente y no conserven o aumenten la temperatura de los tratamientos. Esto a su vez ocasiona que el porcentaje de hu- 
medad no disminuya, ya que no existe evaporación del contenido de agua, lo que provocó que el proceso dure más tiempo.

El compost obtenido tiene una alta salinidad debido al elevado contenido de sales como potasio, hecho que se evidencia en valores altos de $\mathrm{pH}$ lo cual le da un carácter alcalino al medio, propicio para la retención de las mismas. Uno de los factores que pudo haber elevado la alcalinidad en las pilas fue la no generación de lixiviados durante el proceso de compostaje ocasionando la retención de sales disueltas y altos valores de $\mathrm{pH}$. Comercialmente este producto no es competidor con fertilizantes químicos debido a que tiene bajos contenidos de nitrógeno y fósforo, dos de los macronutrientes principales y necesarios en los cultivos. Sin embargo, puede ser usado como acondicionador y mejorador de suelos carentes o con bajos niveles de nutrientes, puede ser útil para cultivo de hortalizas y germinación de semillas, siempre y cuando se lo mezcle con otro tipo de sustratos que garanticen cubrir las necesidadesnutricionales para las plantas, como N, P, K.

\section{Agradecimientos}

Al Centro de Biología de la Universidad Central del Ecuador, por su apoyo técnico y científico.

Al Camal de faenamiento familia Aldaz, por permitirnos realizar la investigación empleando residuos de su proceso productivo.

\section{Referencias bibliográficas}

Andrade, S. (2016). Elaboración de compost a partir de desechos orgánicos con el uso de bacterias ácido- lácticas y Trichoderma spp. en la ciudad de Ibarra (Tesis de pregrado). Universidad de Las Américas. Ecuador. Recuperado dehttp://dspace.udla.edu.ec/handle/33000/ 6165

Arredondo, B., Cordero, B., Herrero, C. y Abalde, J. (1997). Manual de Técnicas Bioquímicas Aplicadas en Ficología. Manual de Prácticas del ler. Curso Teórico Práctico: Aplicaciones Biotecnológicas del Cultivo de Microalgas. La Paz, Baja California Sur, México, pp 1-5.

Cariello, M., Castañeda L., Riobo, I. y González, J. (2007). Inoculante de microorganismos endógenos para acelerar el proceso compostaje de residuos sólidos urbanos. Revista de la ciencia del suelo y nutrición vegetal, 7(3). Recuperado de http://mingaonline.uach.cl/pdf/rcsuelo/v7n3/ art03.pdf

Castillo, H. y Hernandez, A. (2010). Effect of californian red worm (eiseniafoetida) on the nutrient dy- namics of a mixture of semicomposted materials. Chilean journal of Agricultural Research. 70 (3). Recuperado de https://www.researchgate.net/ profile/Hugo_Castillo3/publ ication/262426796_ Efecto_de_la_Lombriz_Roja_Califor niana_Eisenia_foetida_en_la_Dinamica_de_Nutrientes_de_ una_Mezcla_de_Materiales_Semicompostados/ links /551965cb0cf21b5da3b8793b.pdf

Eche, F. (2013). Elaboración de compost, utilizando desechos orgánicos del centro de faenamiento de Julio Andrade. Carchi- Ecuador. (Tesis de pregrado).Universidad Politécnica Estatal del Carchi. Ecuador. Recuperado de http://repositorio.upec.edu.ec/handle/123456789/13

Escobar, N., Mora, J y Romero, N. (2012). Identificación de poblaciones microbianas en compost de residuos orgánicos de fincas cafeteras de Cundinamarca.Scielo.org.16(1). Recuperado de http://www.scielo.org.co/pdf/bccm/v16n1/ v16n1a06.pdf

FAO, (2013). Manual de compostaje del agricultor. Experiencias en América Latina. Santiago de Chile, Recuperado de http://www.fao.org/3/ai3388s.pdf

Gordillo, F. y Chávez, E. (2008). Evaluación comparativa de la calidad del compost producido a partir de diferentes combinaciones de desechos agroindustriales azucareros en Centro de Investigaciones Biotecnológicas del Ecuador. Escuela Superior Politécnica del Litoral. Recuperado de https://www.dspace.espol.edu.ec/ bitstream/123456789/9112/1/Evaluaci\%C3\%B3n\%20 Comparativa $\% 20$ de $\% 20$ la $\% 20$ calidad $\% 20$ del\%20compost. pdf(2008)

Hernández, O., Hernández, A., Rivera, C., Arras, A. y Ojeda, D. (2013). Calidad nutrimental de cuatro abonos orgánicos producidos a partir de residuos vegetales y pecuarios. Terra Latinoamericana. 31 (1). Recuperado de http://www.redalyc.org/ html/573/57327411004/

Instituto de Normalización Chileno, (2003). Norma Chilena 2880. Compost- Clasificación y requisitos.

Santiago de Chile. Recuperado de http://www. ingeachile.cl/descargas/normativa/agricola/N $\mathrm{CH} 2880 . \mathrm{pdf}$

Jia, L., Xiu-hong, X., Hong-tao, L. y Ying, X. (2011). Effect of microbiological inocula on chemical and physical properties and microbial community of cow manure compost.Biomass and Bioenergy.35(8), 3433- 3439. Recuperado de http://dx. doi.org/10.1016/j.biombioe.2011.03.042 
Laboratorios Britania S.A (2015). Tripteína soya agar. Ref. B0210205. Recuperado de http://www. britanialab.com/productos/B23102\%20REV\% 2001-TRIPTEINA\%20SOYA\%20 AGAR.pdf.

Leguizamon, L. y Tique, D, (2008). Protocolo muestras de estiércol vacuno.Recuperado dehttp://proyectobiogas.blogspot.com/

Madigan, M., Martinko, J., Dunlap, P y Clark, D. (2009). Brock. Biologia de los microorganismos. Madrid- España. Pearson. 12 ed.

MAE, (2013). Programa Nacional para la Gestión Integral de Desechos Sólidos - PNGIDS. Ecuador. Recuperado de http://www.ambiente.gob.ec/programa-pngids- ecuador/)

Martí, M., Alonso, R., y Constans, A. (1998). NTP 488: Calidad de aire interior: identificación de hongos.Recuperado de http://www.insht.es/lnshtWeb/Contenidos/Documentacion/FichasTecnicas/NTP/Ficheros/401a500/ntp_488.pdf

Naranjo E, (2013). Aplicación de microorganismos para acelerar la transformación de desechos orgánicos en compost. Universidad Técnica de Ambato. Facultad de Ingeniería Agronómica. Recuperado de: http://repo.uta.edu.ec/bitstream/123456789/5310/1/Tesis - 52\%20\%20\%20 Ingenier\%C3\%ADa\%20Agron\%C3\%B 3mica\%20 -CD\%20173.pdf

Olivares, M., Hernández A., Vences, C., Jáquez, J y Ojeda, D. (2012) Lombricomposta y composta de estiércol de ganado vacuno lechero como fertilizantes y mejoradores de suelo. Universidad y ciencia. 28(1). Recuperado de http://www. scielo.org. $\mathrm{mx} /$ scielo.php?pid=S01862979201 $2000100003 \&$ script=sci_arttext\&tlng=pt.

Pérez, A., Céspedes, C y Núñez P. (2008). Caracterización física-química y biológica de enmiendas orgánicas aplicadas en la producción de cultivos en república dominicana. Revista de la ciencia del suelo y nutrición vegetal. 8 (3). Recuperado de http://www.scielo.cl/scielo.php?pi$\mathrm{d}=$ S0718-27912008000300002\&script=sci_arttext.

Soto, G y Muñoz, C. (2002). Consideraciones teóricas y prácticas sobre el compost, y su empleo en la agricultura orgánica. Manejo integrado de plagas y agroecología. 65. Recuperado de http:// repositorio.bibliotecaorton.catie.ac.cr/bitstream/h andle/11554/5955/A2037e. pdf?sequence =1\&isAllowed = 